\title{
Mooring for floating offshore renewable energy platforms classification
}

\author{
L. Castro-Santos ${ }^{1}$, S. Ferreño González ${ }^{1}$, V. Diaz-Casas ${ }^{1}$ \\ ${ }^{1}$ Department of Naval and Oceanic Engineering \\ Integrated Group for Engineering Research (GII), University of A Coruña \\ Campus Esteiro, C/Mendizábal, 15403, Ferrol, A Coruña (Spain) \\ Phone/Fax number:+0034 981337400 \\ e-mail: laura.castro.santos@udc.es, sara.ferreno@udc.es, vicente.diaz.casas@udc.es
}

\begin{abstract}
Renewable marine energy has emerged as a centrepiece of the new energy economy, because of its abundance, regularity and to be environmentally - friendly. However, its exploitation in a commercial way is constrained due to several engineering problems. One of the mayor of the major constraints when installing this type of structures grounded on the seabed over 100 meters depth. One of the characteristics of the Spanish oceanic coastal shore is its high depth. So, in order to develop any kind of offshore energy in Spain, floating platforms are needed. Besides all of them should be anchored to the seabed. The aim of this article is to characterize mooring system of several floating offshore platforms which are currently designed to support any type of structure for the exploitation of marine energy (wind, waves or tidal energy).
\end{abstract}

\section{Key words}

Anchoring, mooring, floating offshore wind, marine devices, renewable energy

\section{Introduction}

Climate change, the need to reduce atmospheric emissions of greenhouse gases, dependence on fossil fuels, uncertainties concerning on future energy supply and growth of energy prices have turned, in the last years, in to matters of social and political concern.

For this reason, the European Union established in 2007 that $20 \%$ of total energy consumption in 2020 should be obtained from renewable sources [1].

Oceans cover a high percentage of Earth, so offshore energy could be an interesting point of view about how to obtain electricity. But, the majority of the oceans have high depth, so the Danish solution, with grounded systems, is not possible. In this sense, floating offshore platforms solve this problem using mooring and anchoring systems.
Taking into account the way electricity is obtained, there are many types of marine renewable energy sources: tidal, waves, offshore wind, thermal, osmotic and biomass. A functional classification for the mooring systems used for these devices is provided in the following paragraphs. The target is defining a classification independent of the typology of the platform and which allows comparing mooring system typologies.

\section{Mooring systems general classification}

The first step is to classify the types of mooring systems, taking into account the typologies exposed by APL, 1996 Recommended Practice for Design and Analysis of Stationkeeping Systems for Floating Structures [2] for wave energy systems: mooring without tension and mooring with tension, as can be seen in Fig. 1:
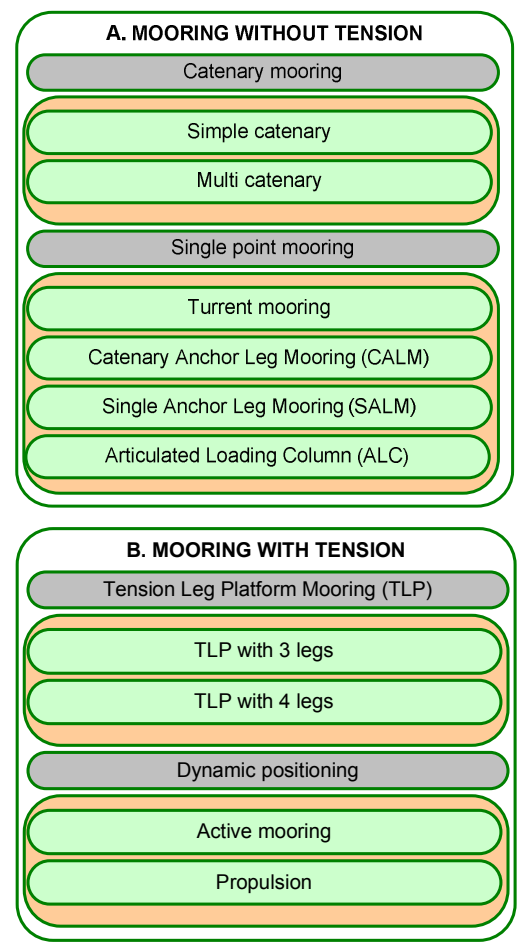

Fig. 1. Mooring classification for floating platforms 
There are two basic types of mooring without tension: catenary and one single point mooring.

The first one, catenary mooring, is a cheap and conventional option, which is used all over the world.

Moreover, the simple catenary mooring reaches the seabed horizontally, so the mooring point only has horizontal loads, being the platform which supports the entire weight of the mooring line.

In the multi catenary mooring, buoys are included, so one part of the weight of the catenary is supported by buoys and the other part by the platform itself.

The second one is the single mooring point, which has the advantage of turning around relatively easily, remaining perpendicular to the direction of the waves. Therefore, the mooring lines can be connected on the other side of the floating system, to keep it in the right position.

Turrent mooring is based on an external or internal catenary which is attached to the platform and to the turrent [3], allowing the flow of movement around this last one.

In the Catenary Anchor Leg Mooring (CALM) the floating structure is moored to a buoy with catenary, allowing the movement around the buoy, which is also attached to the seabed with other catenary [4].

However, in the Single Anchor Leg Mooring (SALM) the floating platform is moored to a buoy, which is attached to seabed with a tension line.

Finally, in the Articulated Loading Column (ALC) the floating structure can move itself around an articulated column, allowing rotation above water line.

Taking into account mooring with tension, Tensioned Leg Platforms (TLP) can have three or four legs connecting the platform and seabed [5].

On the other hand, dynamic positioning system offers the optimum position relative to the crests of the waves, constantly shifting.

Active mooring is composed by several mooring lines around the floating structure, the total number of which are controlled by a servo controller. A central computer changes lines position depending on the sea conditions.

However, in the propulsion mooring, the system depends on propellers, which are also controlled by a central computer.
Fig. 2 shows each of these types of mooring devices:

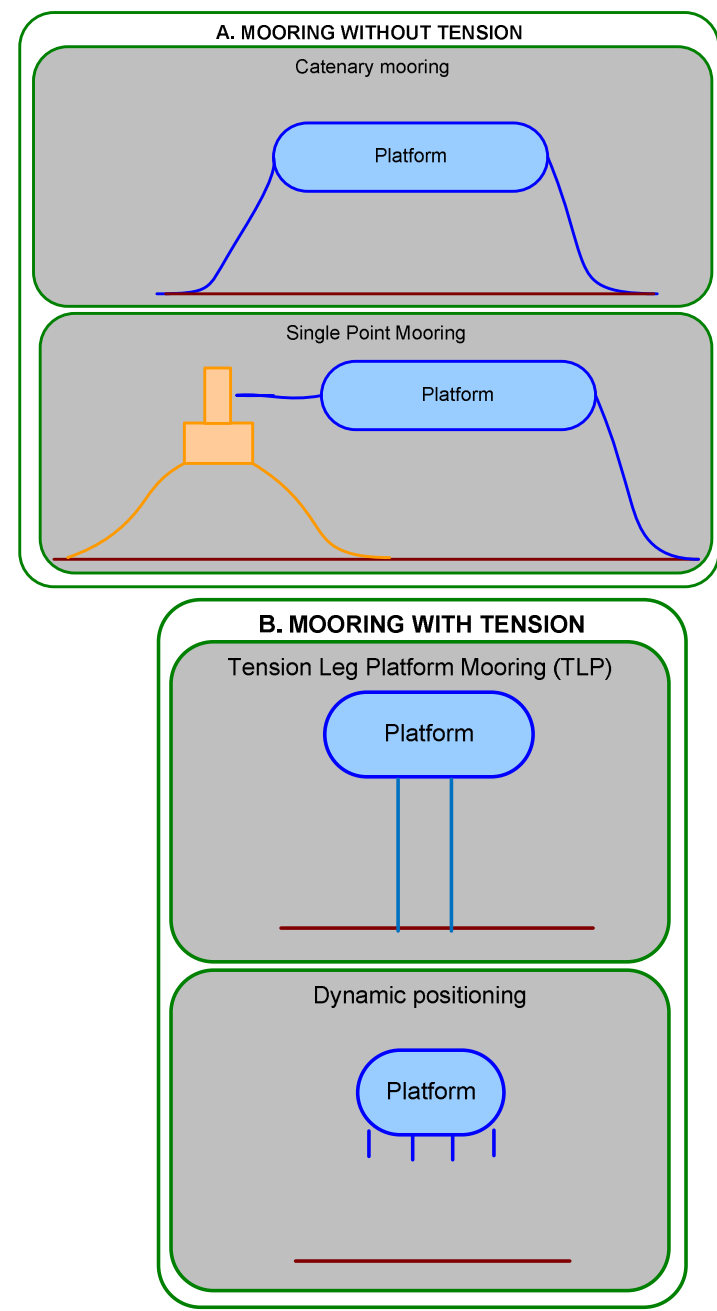

Fig. 2. Mooring devices

\section{Mooring in different type of renewable floating platforms}

System 1 is the Dutch Tri - Floater semisubmersible structure, which is used mainly in offshore wind energy [6]. This structure has six catenary moorings, as we can see in Fig. 3, two in each buoyancy tanks (or columns), and each of them with its anchor. These anchors are suction piles, which can restrict the platform movement [7].

This system is part of catenary mooring, it is said, floating structures without tension. 


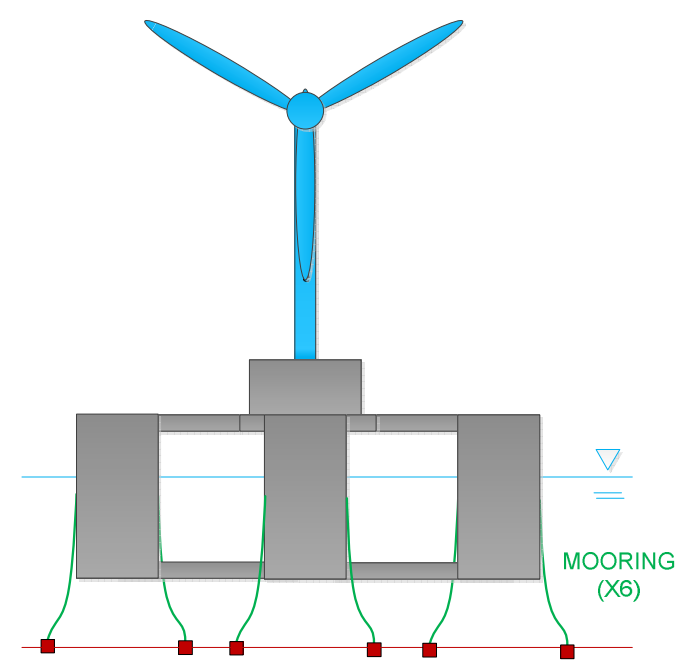

Fig. 3. System 1 [8].

System 2 is also a semisubmersible structure, which is called WindFloat and, like the previous one, is used for generating wind energy. However, the main difference is that here the turbine is not located in the centre [9].

Regarding stabilizing the mooring system, this has six catenary mooring lines, four located on the buoyancy tank where the wind turbine and two mooring devices are placed in the other two tanks [10], as Fig. 4 shows.

This system is also part of catenary mooring, it is said, floating structures without tension.

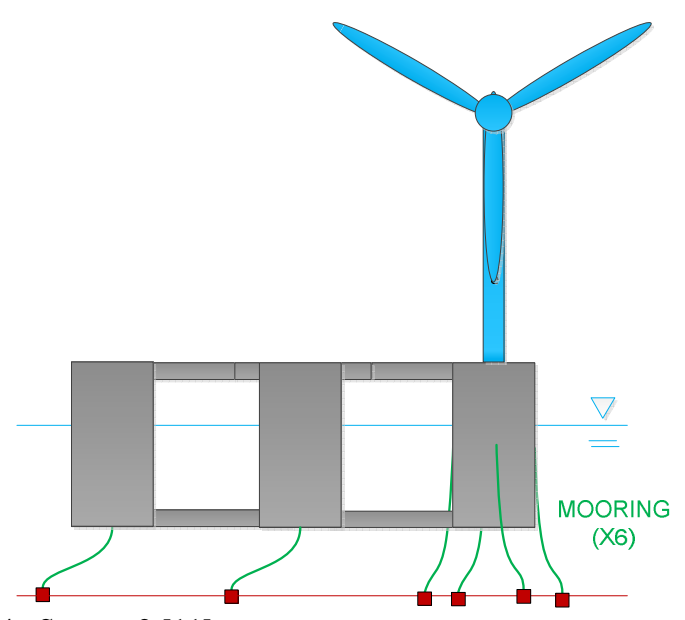

Fig. 4. System 2 [11].

System 3 is the FO3, which is a semisubmersible type of structure used to obtaining energy from waves through a point absorber system [12].

Its mooring system is based on 4 catenary lines, as Fig. 5 shows, being separated on the seabed about $108 \mathrm{~m}$.

This system is, as the previous one, part of catenary mooring, it is said, floating structures without tension.

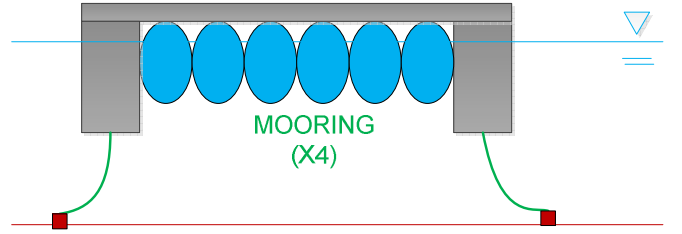

Fig. 5. System 3 [13].
System 4 is a buoy called SeaRev which obtains energy from waves [14].

Regarding its mooring system, it just introduces a single mooring line and a single anchor, as is shown in Fig. 6.

This system is also part of catenary mooring, it is said, floating structures without tension. However, it is included into simple buoys classification.

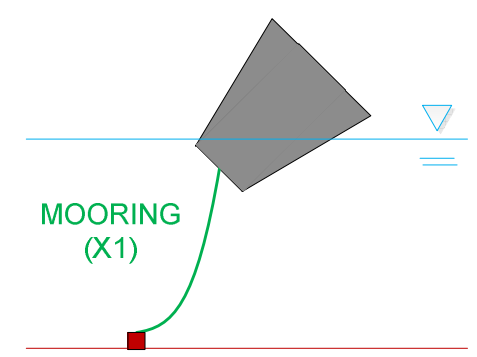

Fig. 6. System 4 [15].

System 5 is the Hywind, which is a spar buoy to obtain wind energy in deep seas. It uses the advances used in offshore oil towers [16].

As far as the mooring system, it consists in three catenary lines, as Fig. 7 shows, spaced $120^{\circ}$. Moreover, it also has three embedded anchors [17].

This system is also part of catenary mooring, it is said, floating structures without tension. However, it is included into spar buoys classification.

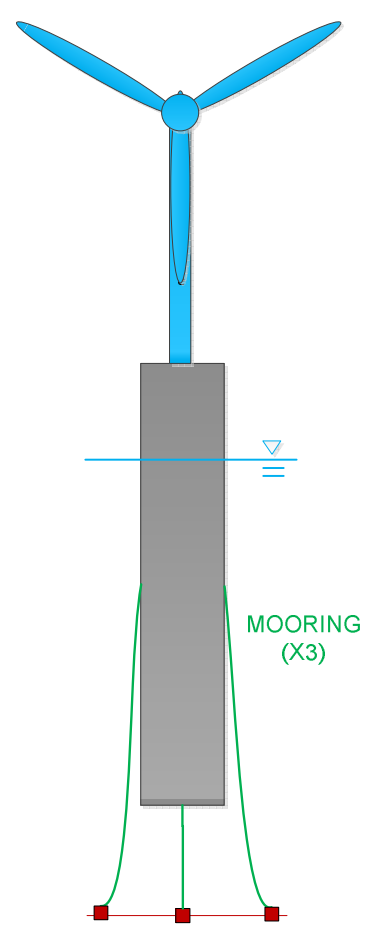

Fig. 7. System 5 [18].

System 6 is the AquaBuoy, and it is a spar buoy with catenary mooring and which converts vertical component of waves in pressurized water, through a special pump [19]. 
This type of buoy is moored by five catenary mooring lines, as is shown in Fig. 8. Furthermore, concerning the anchorages, they are concrete boxes.

This system is also a floating structure without tension, because it is a spar buoy which has catenary mooring.

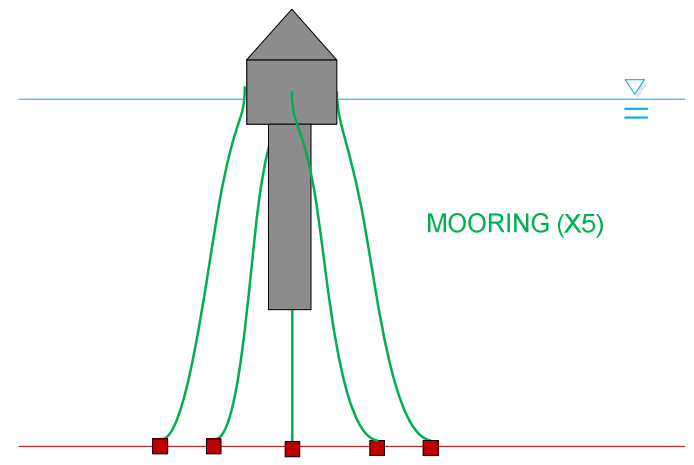

Fig. 8. System 6 [20].

System 7 is the Pelamis, a floating system to generate energy though waves. It is based on a semisubmersed structure and with articulated cylindrical sections connected by joints.

In relation to the mooring system, it is a single point mooring system, similar to that used in ships or FPSO structures, but also it has a retained line in stern, both catenary lines of which are shown in Fig. 9.

So, this system, which is a single point mooring, is included into the floating structures without tension.

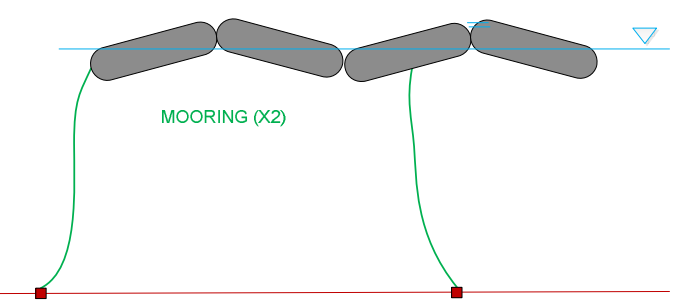

Fig. 9. System 7 [21].

System 8 is a floating platform, but in contrast to systems without tension, it is stabilized by tensioned lines, it is called TLP (Tensioned Leg Platform) [22].

Regarding the mooring system, there are eight tensioned mooring lines, grouped 2 by 2, two for each leg, as we can see in Figure 10, and spaced $90^{\circ}$ and with $127 \mathrm{~mm}$ diameter. Concerning the anchorages, they will be four concrete blocks, one for each two mooring lines [23].

This system, which is a TLP mooring system, is included into the floating structures with tension.

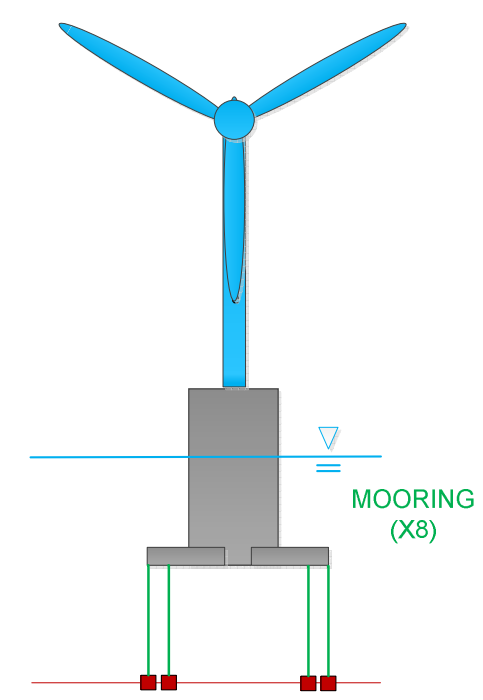

Fig. 10. System 8 [24].

System 9 is similar to system 5, but instead of being anchored with catenary lines and stabilized with ballast, it is fixed to the seabed with a mooring device with tension. It is also used to obtain offshore wind energy.

Regarding the foundation, it will be basically formed by a line with tension and an anchor, as Fig. 11 shows.

This system, which is also a TLP mooring system, is included into the floating structures with tension.

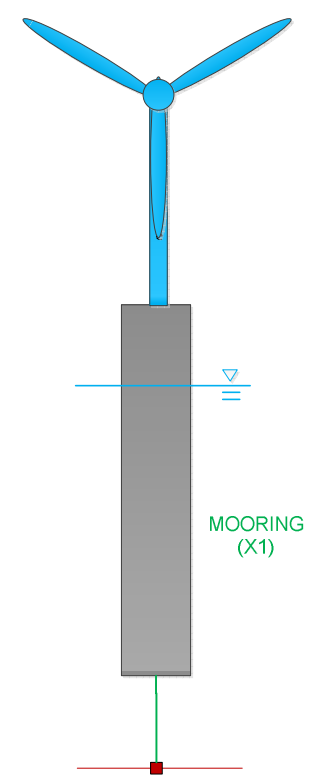

Fig. 11. System 9 [25].

System 10 is called Taut Line Buoy (TLB) and, as Fig. 12 shows, is similar to System 5, but with eight mooring lines, located equidistantly [26].

This system, which is a TLB mooring, is included into the floating structures with tension. 


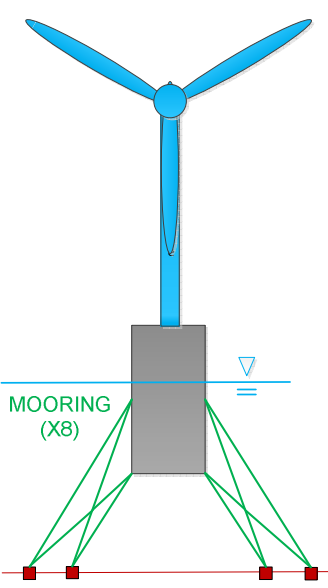

Fig. 12. System 10 [27].

\section{Results}

Mooring analysis was carried out taking into account ten representative prototypes of floating offshore renewable energy platforms.

The first classification is based on the mooring: with or without tension, as Fig. 13 shows:
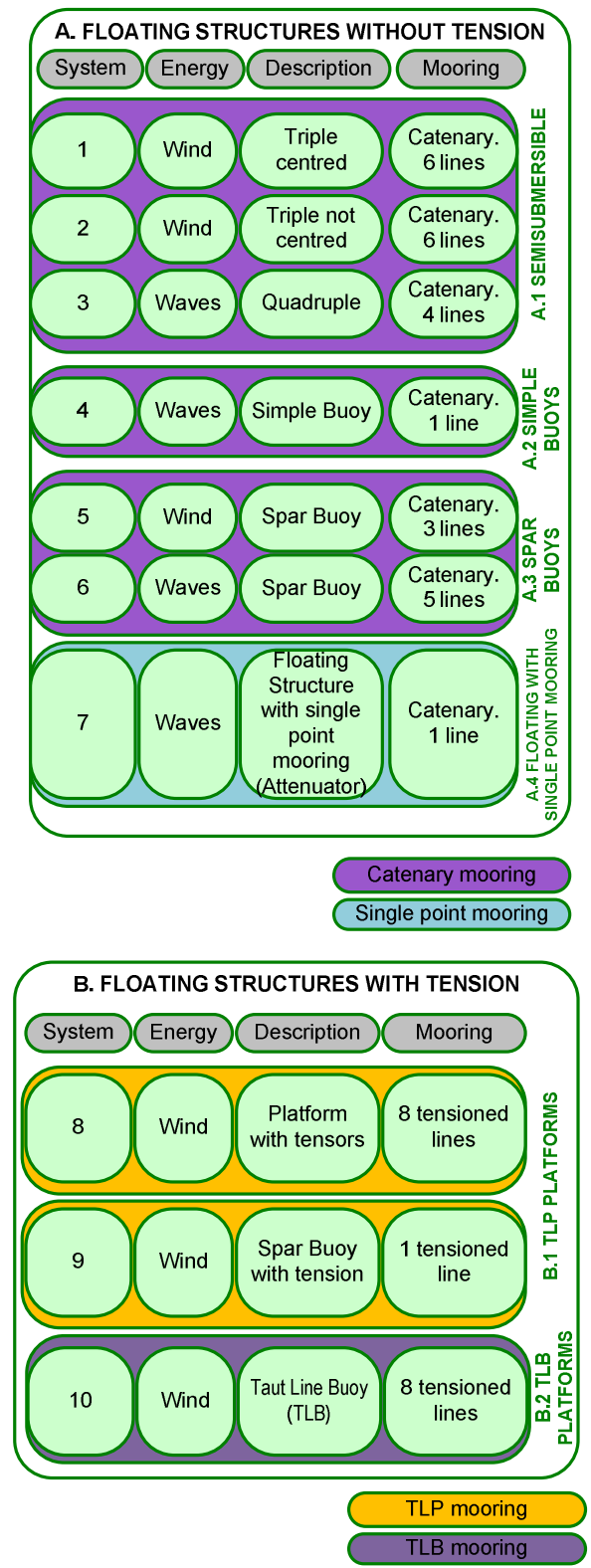

Fig. 13. Selected floating platforms
Finally, and inside the first classification, there is a second important issue, which was used in other previous mooring studies. In this sense, we can differentiate between: catenary, single point, TLP and TLB mooring.

\section{Conclusion}

Nowadays, as we can see, there are a variety of devices in order to obtain marine energy, however, is non - existent a general classification.

Therefore, this article seeks to explain the different types of floating platform moorings, to facilitate their study in the future.

Future works will analyse in depth each of these platforms to determine which ones are better suited for each type of use.

\section{Acknowledgement}

This work was partially funded by the Xunta de Galicia through project 10REM007CT and by Feder founds by the MICIIN through project ENE2010-20680-C03-03

\section{References}

[1] Official Journal of the European Union. Directive 2009/28/EC of the European Parliament and of the Council of 23 April 2009 on the promotion of the use of energy from renewable sources and amending and subsequently repealing Directives 2001/77/EC and 2003/30/EC. 2009 page 16-60.

[2]. American Petroleum Institute (API). API Recommended Practice 2SK. Recommended Practice for Design and Analysis of Stationkeeping Systems for Floating Structures. 1996.

[3] R.E. Harris, L. Johanning, J. Wolfram, "Mooring systems for wave energy converters: A review of design issues and choices". 3rd International Conference on Marine Renewable Energy [Internet]. Blyth, UK; 2004. pp.1-10

[4]. Delf University of Technology. Offshore and Dredging Engineering Group. 2008[Internet]. 2012 [cited 2012 Sep 3]. Available from: http://www.offshoremoorings.org

[5] A.R. Henderson, R. Leutz, T. Fujii, "Potential for Floating Offshore Wind Energy in Japanese Waters". 12th International Offshore and Polar Engineering Conference. Kitakyushu, Japan: International Society of Offshore and Polar Engineers, 2002, pp. 505-12.

[6] W. Musial, S. Butterfield, "Future for Offshore Wind Energy in the United States". EnergyOcean 2004. Palm Beach, Florida (USA), 2004.

ECN, MARIN, Windmaster L the, TNO, TUD, MSC. Study to feasibility of boundary conditions for floating offshore wind turbines, 2002, pp.241. 
[8] S. Butterfield, W. Musial, J. Jonkman, P.D. Sclavounos, "Engineering Challenges for Floating Offshore Wind Turbines". 2005 Cophehagen Offshore Wind Conference. Copenhagen (Denmark), 2005.

[9] C. Cermelli, "Windfloat: A Floating foundation for offshore wind turbines. Part II: Hydrodynamics analysis". ASME 28th International Conference on Ocean, Offshore and Arctic Engineering (OMAE2009). Honolulu, Hawaii (USA), 2009, pp.1-9.

[10] A. Aubault, C. Cermelli, D. Roddier, "Windfloat: a floating foundation for offshore wind turbines. Part III: Structural analysis". ASME 28th International Conference on Ocean, offshore and Arctic Engineering OMAE2009. Honolulu, Hawaii (USA), 2009, pp.1-8.

[11] D. Roddier, C. Cermelli, "Windfloat: a floating foundation for offshore wind turbines. Part I: design basis and qualification process". ASME 28th International Conference on Ocean, Offshore and Arctic Engineering (OMAE2009). Honolulu, Hawaii (USA), 2009, pp.1-9.

[12] Z. Gao, T. Moan, "Mooring system analysis of multiple wave energy converters in a farm configuration". pp.509-18.

[13] A. Leirbukt, P. Tubaas, "A wave of renewable energy". 2006, pp. 29-31.

[14] M. Ruellan, H. Ben Ahmed, B. Multon, C. Josset, A Babarit, A. Clement, "Design Methodology for a SEAREV Wave Energy Converter". IEE Transactions on Energy Conversion. 2010, 25(3), pp.760-7.

[15] Aubry J, Ruellan M, Ben Ahmed H, Multon B. Minimization of the kWh cost by optimization of an all - electric chain for the SEAREV Wave Energy Converter. 2nd International Conference on Ocean Energy. Brest, France, 2008, pp.1-7.

[16]. J. Jonkman, "Definition of the Floating System for Phase IV of OC3". 2010.

[17] J. Jonkman, A. Hansen, T. Nygaard, K. Maus, M. Karimirad, et al., "Offshore Code Comparison Collaboration within IEA Wind Task 23 : Phase IV Results Regarding Floating Wind Turbine Modeling". European Wind Energy Conference (EWEC) 2010. Warsaw, Poland: NREL (National Renewable Energy Laboratory), 2010, pp.1-23.

[18] Statoil. Página Web Statoil [Internet]. 2012 [cited 2012 Sep 3]. Available from: www.statoil.com

[19]. A. Weinstein, G. Fredrikson, M. Jane, Group P Denmark KNR, "AquaBuOY - The Offshore Wave Energy Converter Numerical Modeling and Optimization". 2001, pp.1854-9.

[20] Aqua Energy Group. Aqua Energy Group [Internet]. 2012 [cited 2012 Oct 25]. Available from: http://aquaenergygroup.com/
[21] Pelamis. Pelamis wave power [Internet]. 2012 [cited 2012 Oct 25]. Available from: http://www.pelamiswave.com/

[22] Massachusetts Institute of Technology. Laboratory for Ship and Platform Flows, Department of Mechanical Engineering [Internet]. 2012 [cited 2012 Oct 25]. Available from: http://web.mit.edu/flowlab/

[23] C.M. Wang, T. Utsunomiya, S.C. Wee, Y.S. Choo, "Research on floating wind turbines: a literature survey". The IES Journal Part A: Civil \& Structural Engineering, 2010, 3(4), pp.267-77.

[24] D. Matha, "Model Development and Loads Analysis of an Offshore Wind Turbine on a Tension Leg Platform, with a Comparison to Other Floating Turbine Concepts". 2010, pp.1-129.

[25] Sway. Página Web Sway [Internet]. 2012 [cited 2012

Sep 3]. Available from: www.sway.no[26] P.D. Sclavounos, S. Lee, J. DiPietro, "Floating Offshore Wind Turbines: tension leg platform and taught leg buoy concepts suppoting 3 - $5 \mathrm{MW}$ wind turbines". European Wind Energy Conference (EWEC) 2010. Warsaw, Poland, 2010.

[27] K.H. Lee, "Responses of Floating Wind Turbines to Wind and Wave Excitation". Massachusetts Institute of Technology (MIT), 2005, pp.1-55. 